\title{
Repositioning of CLT from Curriculum to Classroom: A Review of the English Language Instructions at Bangladeshi Secondary Schools
}

\author{
Md. Zulfeqar Haider ${ }^{1}$ \& Takad Ahmed Chowdhury ${ }^{2}$ \\ ${ }^{1}$ Foreign Language Training Center, Ministry of Education, Dhaka, Bangladesh \\ ${ }^{2}$ Department of English, University of Asia Pacific (UAP), Dhaka, Bangladesh \\ Correspondence: Takad Ahmed Chowdhury, Department of English, University of Asia Pacific, House \# 8/A, \\ Road \# 7, Dhanmondi, Dhaka-1209, Bangladesh. Tel: 880-2-967-3057 (Extn.117). E-mail: takad@uap-bd.edu
}

Received: May 6, 2012 Accepted: May 28, 2012 Online Published: June 20, 2012

doi:10.5539/ijel.v2n4p12 URL: http://dx.doi.org/10.5539/ijel.v2n4p12

\begin{abstract}
This paper attempts a study of the present state of teaching and learning English at the secondary schools in Bangladesh. It offers an analysis of the current English curriculum and textbooks for the secondary grades and explores the current classroom practices through classroom observation and teachers' interview. The classroom observations were conducted to identify the features of Communicative Language Teaching (CLT) approach prescribed by the curriculum and syllabus document of National Curriculum and Textbook Board (NCTB) as the desired approach for teaching English at secondary level schools in Bangladesh. The paper also attempts to identify connections between the curriculum objectives and the classroom realities faced by the teachers and seeks suggestions for achieving the stated objectives. Some of the key recommendations include - strengthening of the teacher development initiatives, redefining the entry and exit levels of the learners, providing alternative and supplementary instructional materials and reforming the assessment system.
\end{abstract}

Keywords: CLT, EFL, curriculum change, teachers' role, Bangladesh

\section{Introduction}

The English curriculum for secondary schools of Bangladesh (grades 6 to 10) was revised by the National Curriculum and Textbook Board (NCTB) in the 1990s as an attempt to address the growing concern about the continuing deterioration of the standard of English language teaching in the country. In 1995 NCTB revised the English curriculum with a move to introduce "Communicative Language Teaching" (CLT). The CLT approach was introduced with the hope of developing a workforce with "communicative competence" in English that should, thus, strengthen the human resource development initiatives of the country (Hamid \& Baldauf, 2008). The objective behind introducing CLT is stated in the NCTB document, which says,

English needs to be recognized as an essential work-oriented skill that is needed if the employment, development and educational needs of the country are to be met successfully. English should, therefore, be taught as something to be used, rather than as something to be talked about. (NCTB, 1996: 135-136)

However, despite the introduction of a communicative syllabus, NCTB had the realization that a syllabus alone could not ensure the implementation of communicative language teaching and learning in the classroom, it could only provide a set of criteria for a change. Therefore, in order to get the best out of the new syllabus a number of reform initiatives such as preparing suitable teaching materials, arranging teacher training and bringing about changes in the examination system were recommended. Accordingly, a set of new communicative textbooks was published.

The curriculum document of NCTB clearly puts emphasis on the development of the communicative competence of the learners in English so that they can meet the ultimate development needs of the country. Hence, it is of paramount importance to look at the successful implementation of CLT as it is related to the overall human development agenda of Bangladesh as stated in the curriculum document. It has been more than a decade since CLT was introduced in the secondary EFL classrooms of Bangladesh but the impact of this methodological change has been under-researched. This study looks at the English language teaching and learning practices in selected secondary schools and attempts to relate them to the features of CLT as mentioned 
in the NCTB curriculum document. The study also aims to identify the problem areas that impede the successful implementation of CLT at the secondary EFL classrooms of Bangladesh and seeks suggestions to deal with them.

\subsection{Previous Research}

Some baseline surveys have been conducted to generate information on the state of English Language Teaching (ELT) in Bangladeshi schools. The baseline study of English Language Teaching Improvement Project (ELTIP), conducted in 1998, found the majority of teachers practicing traditional modes of teaching in their classrooms. The findings from the proficiency testing results of the same survey also demonstrate a miserable picture of the overall English language proficiency of the learners as well as the teachers. One of the baseline studies done by English in Action (EIA) project in 2008-9 on the spoken English competence of the students, teachers and adults found that the spoken English competency of most Bangladeshi students, teachers and community adults was at a basic level (P. 14). It was reported that even after many years of schooling a lot of students had not progressed beyond the initial stage of speaking in English (p. 26). The study also revealed that the teachers were unable to effectively teach the higher levels of the communicative English curriculum due to their poor English language skills. Another study undertaken by EIA project observes that in most English classes at secondary and primary schools, teachers follow instructive and top down model of teaching and there was little use of interactive method. The study reports more traditional pedagogic practices in the classrooms in which students were mainly "passive learners". In his study on the communicative teaching practices at the higher secondary institutes of Bangladesh, Islam (2011) observes the teachers' reluctance to promote CLT and indicates that many teachers avoid the few ideas of CLT that they held (p. 384). There are some other reports confirming the similar facts about implementation of CLT in the classroom (Rahman, 1999; Hamid, 2005; Hamid \& Baldauf, 2008).

All the above mentioned works have provided a base for undertaking the current research. However, the current study is particularly concerned with the issue of rethinking the nature and scopes of CLT in the prevailing classroom realities of Bangladesh. The study not only looks at what's happening in the classroom but also aims at relating these findings to the possible innovations that can be incorporated in the CLT approach in addition to what has already been specified by the curriculum. Thus this study has very significant implications for the teachers, students, curriculum designers, textbooks writers, examiners and policy makers of secondary English education sector in Bangladesh.

\subsection{Importance of the Problem}

English is increasingly becoming the dominant factor for the development of a country as it has been dominating the choices and opportunities in education, technology and global trades and business. A creative and adaptive workforce with English language proficiency is now essential for fostering a nation's socio-economic development. However, achieving the command and mastery in English is a challenging task particularly in a developing country like Bangladesh. After four decades of independence, Bangladesh is yet to formulate a clear policy for the status, uses and teaching of English at both academic and real life contexts. Consequently, not surprisingly, the country is struggling to produce a generation having high level of proficiency in English. Such situation obliges to rethink about the existing teaching methods of English.

At the dawn of the new millennium, the National Curriculum and Textbook Board (NCTB) of Bangladesh revised the English curriculum and introduced the Communicative Language Teaching (CLT) approach for teaching-learning of English at the secondary level. It was expected that students would achieve mastery of English as well as be respectful and devoted to the use of Bangla, the mother tongue. Some researchers argue that (Afroze \& Rahman, 2008; Rahman, 2011) after more than a decade of introducing CLT, students of secondary schools are still struggling to achieve desired level of proficiency in English. Under such circumstances, there is a need for rethinking the effectiveness of CLT in terms of the existing classroom realities of Bangladeshi secondary schools. Hence, the study aims to explore the existing ways of teaching English in secondary schools as well as relate those to the pedagogic features specified by the curriculum. Moreover, the study aims to identify ways of adjusting the features of CLT to Bangladeshi classroom realities.

\subsection{Literature Review}

CLT is an umbrella approach to language teaching which is essentially progressive in nature. It originated in the UK in the 1960s (Wright, 2000). In CLT "The heart of the language lesson is the communicative activity itself" (Howatt, 1984: 279). The idea of communicative language teaching emerged in the 1970s following Hymes' (1972) theory of communicative competence, which greatly emphasized learners' ability to use language in context, particularly, in terms of "social demands of performance" (McNamara, 2000: 116). Hymes believes that knowing a language is more than knowing its rules. After Hymes had proposed the idea of communicative competence, it was expanded in various ways during the following two decades. The term competence was 
interpreted in many different ways by researchers. To some it simply means the ability to "communicate"; to others it means the social rules of language use; and to yet other, it refers to a set of abilities including knowledge of linguistics, socio-linguistics and discourse rules (Bachman \& Palmar, 1984: 34).

The principles of CLT include concentration on "use" rather than "usage" of English with focus on fluency than accuracy (Widdowson, 1978; Littlewood, 1981). CLT has a focus on communication tasks to be achieved through the language rather than exercises on the language. It emphasizes students' initiatives and interactions rather than teacher-centred interactions (Maley, 1986: 86). CLT does not promote the idea of achieving the purely "linguistic" competence of learners, which is concerned only with the tacit knowledge of language structure. It is concerned with linguistic performance, a process related to encoding and decoding a language (Hedge, 2000). CLT also aims at integration of skills rather than practicing them isolation (Widdowson, 1978; Littlewood, 1981; Hedge, 2000) and it has an awareness of variation in language use rather than attention to the language itself (Trudgill \& Hannah, 2002). Therefore, it is opined that the goal of communicative teaching is to develop an ever-improving capability to use English to communicate with others and to develop and apply anincreasing understanding of how English is organized, used and learned (Clark et al., 1994: 37).

Hence, the dimensions of communicative competence which are identified in the literature include: linguistic or grammatical competence, sociolinguistic or pragmatic competence, discourse competence, strategic competence (Richards \& Rogers, 1986; Hedge, 2000), and fluency (Hedge, 2000). Communicative Language Teaching is best considered as an approach rather than a method (Richards \& Rogers, 1986). However, the basic idea of communicative competence remains the ability to use language appropriately, both "receptively and productively, in real situations" (Kiato et al., 1996: 1).

\section{Method}

\subsection{Description of Research Method}

The research is primarily based on qualitative study of teachers' and learners' behavior within the EFL classroom. The data were collected from eight secondary schools of Bangladesh and a total of sixteen lessons were observed, two lessons of grade ix in each school. Moreover, semi-structured interviews were conducted with the sixteen teachers whose lessons had been observed. As for primary data, the English curriculum and syllabus document of NCTB, the textbook for grade ix titled, English for Today (EfT) and the assessment format of the school terminal test of the same grade have been examined.

\subsection{Sample Size and Procedure}

The eight schools for classroom observation were purposively selected from both urban and rural areas under Dhaka district. The sample size contained a balance of government and non government schools with both boys and girls students and male and female teachers. The sample size was kept limited to only eight schools considering the financial and time constraints. All the selected teachers had at least five years of teaching experiences with professional training on CLT.

\subsection{Tools for Data Collection}

For recording the findings of classroom observation, a checklist was prepared with fifteen statements to be agreed with on a five-point-scale with 1 denoting "strongly disagree" to 5 "strongly agree". The questions were prepared to focus on six broad areas of the lessons observed (Appendix1). A semi structured questionnaire was also prepared to conduct the interview with teachers. The questionnaire had eight open ended questions. However, as the interviews were conducted face to face, there were scopes to include supplementary questions too. (Appendix 2)

\section{Result}

\subsection{A Review of the Curriculum and Textbook}

In Bangladesh, the textbooks from primary to higher secondary levels are centrally published and distributed by NCTB. Generally the schools do not have any teaching materials other than these textbooks. Ideally, the textbooks should come with teacher's guides but due to various reasons these are not available to teachers. Though the curriculum documents suggest for additional materials such as students' workbooks and simplified readers, these are non-existent in most of the schools. Both the textbooks and the teacher's guides are monocolored, newspaper-printed materials with unattractive, small sized, hazy drawings. Moreover, there is criticism that the textbooks are too easy for some of the urban schools but difficult for many rural schools. The textbooks are written following communicative approach and, so, they emphasize communication rather than teaching of literature. 


\subsection{Textbooks and Learning Materials}

The present English syllabus of NCTB is based on a "language deficit" theory (Howatt, 1984: 279), where efforts are taken to improve learners' communicative skills by providing a "richer" linguistic environment. Here, the primary duty of a teacher is to ensure that the students' knowledge (in English) is usefully employed for communicative purposes. Therefore, it can be said that the basic aim of the present syllabus is to promote the "communicative performance" (Nunan, 1987: 141) of learners and it emphasizes learning English through communication. The kinds of activities available in the present textbook are: talking about pictures, guessing about picture, matching pictures, asking questions (guided), interviewing partners, writing article based on partner's responses. All these activities have functional purpose. There are other activity types also which highlight the functional and social interactional purposes of the textbooks. Examples of such activities are: matching signs with instructions, describing a process, telling stories from pictures etc.

The activities in the EfT textbook listed above are organized round a series of communicative tasks, graded in order of conceptual difficulty, beginning with very simple tasks like labeling and then moving towards more complex ones. Primarily, the emphasis is given on comprehension. Later, as the learners' "internal grammar" matures and their capacity to generate language of their own strengthens, language forms deviate from easy to standard. The analysis also helps us to classify the activities of the textbooks in the following way:

- Sharing information with restricted cooperation such as identifying pictures, discovering identical pairs, discovering sequence of locations, discovering missing information, discovering missing features, discovering secrets etc.

- Sharing information with unrestricted cooperation such as communicating patterns and pictures, communicating models, discovering differences, following directions etc.

- Sharing and processing information of different kinds such as reconstructing story-sequences, pooling information to solve a problem.

- Processing information where learners are asked to imagine what they are going to do in an imaginative situation and interact with each other or the teacher.

(Haider \& Roy, 2006, 3-4)

At the same time, throughout the course, learners are supposed to pay greater attention to the social as well as the functional meanings that language conveys, which is supported by Littlewood (1981: 42). Language activity types include dialogues, role-plays, conversation or discussion, simulation, role-playing etc.

Therefore, it can be said that the current NCTB syllabus represents an integrated framework, which intermingles different versions of communicative syllabuses such as competence based, text based and task based ones. It is also a blend of two/three syllabus strands such as grammar linked to skills, and sometimes tasks linked to topics or functions.

The existing curriculum and syllabus of NCTB does not ignore the importance of grammar. Rather, a comprehensive and rationally organized grammar is integrated in to various elements of the revised textbooks. However, since grammar teaching is not overt, often teachers find it difficult to identify the grammar focus of a lesson from the given contexts. They also misunderstand the functional use of grammar within appropriate contexts and realistic communicative situations. Sensing this problem, NCTB has recently added formal grammar teaching as Paper 2 in addition to EfTs from class six to twelve.

\subsection{Teaching Methodology}

The curriculum document of NCTB for classes 6-12 narrates the teaching methodology in the following words:

Successful teaching and learning of English ultimately depends on an effective teaching methodology. The chief aim of such a methodology must be to give learners as much practice as possible in the use of English. Since language is a participatory activity, a successful language teacher will have a close personal rapport with his/her students, both as a group and as individuals. In language learning based on communication, therefore, good classroom relationships are of particular importance. Consequently every language teacher should know all the students' names as soon as possible after taking a new class. The students should know and use each other's names as well.

(NCTB, 1996: 153)

A list of criteria essential for effective teaching and learning is also specified in the curriculum document. These 
include:

a) Varieties of activities and skills with maximum students' involvement.

b) Clarity from teachers in presenting structures and vocabulary and maximization of using English for students' maximum practise in the target language.

c) Use of English from classroom management to giving instructions. Bangla can be used as a "checking device where the teacher feels it appropriate to ensure that the English has been correctly understood".

d) Students would spend more time talking than the teachers so that they can internalize the language from the classroom.

e) Students should be trained to work in pairs and in groups in the classroom for promoting cooperation. During the pair or group work, teachers will do the necessary monitoring.

f) Teachers will ensure that the writing activities in the books are done either in the classroom or at home. Students' writing should be checked by the teacher in a regular basis.

g) For students' better understanding and ensure quick reading ability, opportunities will be created for silent reading.

h) Teachers would not be "fussy" about students' mistakes and would not emphasize only "grammatical accuracy". Teachers should keep in mind that their main job is to increase students' motivation in using English.

(NCTB, 1996: 153-154)

\subsection{Students' Learning Outcomes}

The learning outcomes of classes 6-12, as mentioned in the curriculum document are:

a) The specific objectives of teaching and learning English are spelt out in terms of four language skills of listening, speaking, reading, and writing.

b) For convenience in defining learning outcomes, the four skills are considered separately. In practice, however, classroom activities should be planned so as to fully integrate these skills, as happens in real life.

c) By defining learning outcomes in terms of skills, the syllabus aims to facilitate a teaching methodology that encourages learners to acquire communicative competence through regular practice of these skills in the classroom. Such a methodology (described in greater detail below in section 9) is learner-centered (rather than teacher) and is characterised by lively student participation, especially in pairs and groups.

(NCTB, 1996: 135-136)

\subsection{Assessment Strategies}

The NCTB curriculum has recommended 3 types of tests for evaluating learner's achievement/proficiency level: a) continuous assessment, b) internal examinations, and c) the public examination. The three main functions of tests and examinations as described in the syllabus are:

- to ascertain the extent to which students have attained the stated learning outcomes;

- to identify students' strengths and weaknesses for the purpose of guiding subsequent teaching and learning;

- to motivate students by giving them a regular sense of achievement and to make their parents aware of their progress.

(NCTB, 1996: 146)

In order to carry out these functions properly it is necessary to test students' language skills, but unfortunately, the existing assessment system is chiefly memory based. At the same time, in most of the schools there is no generally agreed system for continuous assessment.

The test items suggested in the sample papers in Teacher's Guides do not often relate to any of the four skills. 
Two important skills-speaking and listening are totally excluded from the test format while the testing of the two other skills-reading and writing has very little elements of validity and reliability. Some problems of the test items currently used to test students' reading and writing skills are as follows:

The test of reading: In the existing test format learners' reading skills are tested by asking candidates to read a text and then to answer various types of questions based on the text. The question types are: multiple choice, true/false, filling in gaps with/without clues, cloze test, information transfer, making sentences from substitution table, matching words, and open ended questions.

These test items are considered as fairly good items to test reading skills. However, the problem is that the test setters are not trained and experienced enough to design test items which are based on testing candidate's communicative competences. In fact, many of the test items set by the test setters, both for the school tests and public examinations such as the Secondary School Certificate (SSC) examination contain very little communicative content. For example, the multiple-choice or true false questions (as found in the SSC questions) are often unrelated to the nature of communicative language in use. Candidates facing such items have a chance of answering those questions not by comprehension but by using some other strategies, like eliminating the ones that must be wrong.

The test of writing: In the second paper particularly, students are asked to write letters, passages and essays. The writing tasks often do not clarify the purpose, audience or genre of the writing. If students are communicating, there has to be a purpose of that communication. In order to have a purpose they need to have a proper context, and for that, there should be an audience, at least, some ideas.

Composition topics: Writing essays on topics like "Your Favorite Teacher", "The Rainy Season", "The Post man” are kinds of very typical and decontextualized essay topics. Moreover, teachers can easily guess such traditional topics for their students who have got good memory, and they are quite good at memorizing texts. Memory is an important component of language learning but it's not the same thing as language use.

The marking of writing: Another problem with the writing tasks given in the test question is that they don't explain the assessment criteria; students are only asked to write but they have no idea about whether they are going to be marked on content or on the accuracy. As a result, some students put emphasis on the length of writing, whereas others on accuracy; to yet another, argument may become more important than the length or the accuracy. Same is the case with the markers. They vary considerably in their notion of what makes a good piece of writing. The problem is there is no clear guideline to ensure inter-marker reliability.

\subsection{Findings from Classroom Observations}

\subsubsection{Medium of Instruction}

Regarding the medium of instruction in the English language classes, only 2 teachers were found using English throughout the lesson for giving instructions. The rest of the teachers used a mixture of both Bangla and English as medium of instruction. While reading the English text aloud to the students most teachers used Bangla translations to explain the meaning of the text. Teachers had a tendency of slipping in to Bangla after starting a sentence in English.

\subsubsection{Techniques of Reading}

While dealing with reading texts 9 teachers were reading them aloud and 3 were asking students to read silently. As for reading by students, 13 teachers were found instructing the students to read aloud. Only 4 teachers set some pre reading activities before asking students to read while 6 teachers introduced some vocabulary before setting the reading tasks.

\subsubsection{Techniques of Generating Grammar}

When it came to the question of teaching grammar, a majority of 12 teachers were found teaching grammar by explaining the rules and structures explicitly. Only 3 teachers were found using the contents of the English textbooks for generating grammar points. It is evident that grammar items were often presented to the students by teacher as s/he often referred to the grammatical explanations, rules and definitions. There was no evidence of teaching grammar in communicative contexts.

\subsubsection{Warm-up Activities}

Only 7 teachers were found using warm-up activities, such as, using pictures or games etc. at the beginning of the lesson. The rest 11 teachers were found starting the lessons straightway without any warming up. Moreover, warm up activities are hardly in evidence during classroom observations. 


\subsubsection{Presenting Vocabulary}

While teaching vocabulary, the most commonly used technique was explaining the word in Bangla or giving the L1 equivalent of the word. Only two teachers were found explaining the new words in English. Among other techniques 3 teachers used inference as a means of making learners understand new words. No teachers were found to have used any visual aids for presenting new vocabulary items.

\subsubsection{Students’ Interaction Pattern}

Regarding the interaction pattern, 4 teachers were found to engage learners in pair works while only two teachers set group works for the learners. However, it was observed that pair works and group works were not practiced in most of the classes for most of the times.

\subsection{Findings from Teachers' Interview}

\subsubsection{Teaching Learning Situation}

While talking to the teachers, it was revealed that they prefer sticking to the teacher-centered approach of teaching as it gives them "command" over the students' learning. Moreover, some teachers are with the belief that a teacher centered classroom enables them to complete a lesson smoothly and in time. It is clear from the finding that no one has ever challenged their authority or raised any questions about their established practice. Now when they are invited to consider exploratory learning or interpretive learning, they find a mismatch between their old practice and what is now being suggested.

\subsubsection{The Role of Students}

Most teachers held the view that traditionally, learners in Bangladeshi schools are the passive receivers of knowledge and the learners believe that they have nothing much do, as their teacher is responsible for doing everything. According to the teachers, in a culture like this, the learners feel shy and reluctant to speak out. Moreover, some teachers admit the fact that learners are not encouraged by teachers to ask questions and they always feel insecure and helpless about making mistakes. Therefore, learners prefer it to keep silent and listening to their teachers most of the time.

\subsubsection{Nature of Interactions}

The scope of communication between and among students or between students and teacher or vice versa is obviously helpful for students to master the target language. It is already evident from the review of the EfT textbooks that they provide lots of interactive activities for the learners. In their response many teachers admit that they do not take the pains of engaging their students in interacting with one another.

\subsubsection{Dealing with Errors}

In a communicative classroom, learners' errors are seen as healthy steps towards perfection. Teachers need to encourage their learners to use the language fluently instead of interrupting them for any mistake they make. Thus, a communicative classroom creates the opportunity of encouraging the shyer and weaker students to speak out. While responding to the question about dealing with students' errors, majority of the teachers said that they do not have enough time to give constructive feedback to the learners. It is also evident from classroom observation that the teachers of Bangladesh have neither the skills nor the patience of correcting their students' errors gently. By doing this, they are causing serious damages to the very spirits of a communicative classroom.

\subsubsection{Role of Mother Tongue}

Frequent use of mother tongue is discouraged by CLT curriculum and methodology. It is suggested by teachers that mother tongue will be used only when there is no alternatives. Students are expected to learn from the "English environment" created within the classroom. Again, the biggest problem here, as revealed by the teachers, is they prefer Bangla as a medium of instruction even for their English lessons due to their poor level of proficiency in English. It ultimately has an adverse effect on learners' proficiency in the target language.

\section{Recommendations}

The features of CLT and the criteria set for teaching and learning in the curriculum documents provide the opportunities for the teachers and learners to improve their practices and attitudes. However, the present realities do not replicate the methodological aspects suggested in the curriculum documents. In fact, the implementation of the methodological underpinning of the communicative approach is being impeded by many constraints that exist in the present teaching-learning context. To overcome those problems, teachers were asked to suggest ways for adjusting the features of CLT within their classroom realities. The teachers suggested measures for improving the teaching learning practices especially in communicative teaching situation. They help identify a number of 
opportunities offered by CLT to enhance the learners' proficiency in English. The suggestions made by the teachers are summarized below:

\subsection{Teacher Development}

In Bangladesh, at present there are many teacher training programmes for the secondary level English language teachers such as the training offered by PACE, ELTIP, TTCs, NAEM, SESIP and TQI. These are basically short in-service training (INSET) courses on ELT. Teachers, who are doing well in the training rooms, unfortunately stick to their traditional practices as soon as they leave the training room island. All over the world, now-a-days, the effectiveness of short inset courses is being questioned, as they fail to create the motivation within the teachers which initiates a long term change. At the same time, resistance from the existing system, noncooperation from higher authorities and teachers' professional isolation sometimes hook them to go back to their old practices. Therefore, instead of short INSET courses designed on foreign models, initiatives can be taken for improving teachers' motivation for continuous professional development. For this to do, initially long term habit formation is needed through sufficient real classroom practices. In that case, courses could be structures according to the real needs of teachers. Such long-term activities should be culturally and financially viable too and they should not be one off. Moreover, a teacher development courses should include some components of developing teachers' own English. And, a regular monitoring system is essential to ensure quality and harmony in this sector. Hence, there is a need to re-think about the nature and purpose of the existing teacher training programmes. It is time to think about a training, which, instead of imparting knowledge, would engage our teachers in a dialogue through which we could collaborate in shaping the content and methodology of such training.

\subsection{Alternative Learning Materials}

Among other suggestions the teachers recommend that the existing textbooks be supplemented with a set of learning materials that might include students' work book, bridging materials, simplified teachers guides and extra materials like pictures and visuals.

\subsection{Describing the Entry and Exit Level}

The NCTB syllabuses describe the class-wise competencies that the learners of a particular class are going to achieve. However, teachers often talk about the 'poor' level of their learners' English. For example a large number of teachers, particularly those in the rural secondary schools, believe that students enrolled in class six have no idea about parts of speech, subject-predicate or even the English alphabets! Therefore more detailed descriptions are needed for students' proficiency level before they enter a class. Information may be available on students' entry level from specially designed tests. And, on the basis of the findings of such tests, a bridging course may be introduced to ensure that the learners have the same language ability, at least, in terms of the basic language knowledge required to undertake a particular program. The existing vertical and horizontal gaps between the primary school leavers and secondary school beginners have to be identified and it could be bridged through a 2/3 week remedial program before taking the learners to grasp class six syllabuses.

\subsection{Reformation of Assessment System}

The following recommendations emerged from the teachers' responses to help improve the quality of the current testing practices:

1. The curriculum needs to specify more particularly the purpose and objectives for English language use and the test format must reflect these purpose and learning outcomes.

2. The current test format could incorporate the tests of listening and speaking skills-at least in the school based testing system.

3. Teachers and markers need to be trained on language testing issues and they have to be aware of the validity and reliability of a test.

4. The reading test items might be chosen in a way so that they can replicate the real ability of candidates' reading skills.

5. The writing tasks should offer the candidates a meaningful context, a purpose and an audience. Test takers should know about what genre of writing they are to produce and what aspects of their writing are going to be assessed.

6. The test setters should produce a clearly defined marking scheme both for the objective and more free test items. 


\section{Conclusion}

The initiative of introducing CLT at the secondary and higher secondary levels by revising the ELT curriculum marked a paradigm shift of NCTB from traditional teaching to a new approach. It is evident from the review of the textbook that the new textbooks well reflect the objectives of the new curriculum and CLT. They can be potentially used to improve our learners' language skills, provided the other conditions are fulfilled properly. The findings from the classroom observation reveal the fact that there are little exposures to communicative language use in the English classroom. In their interview the teachers pointed out some impediments to effective use of the communicative textbooks and approach. It is reported that lack of trained and competent teachers, faulty assessment system, and shortage of supplementary and bridging materials have made the whole process hard to reach. To achieve the maximum benefits from the current curriculum and textbooks, sustainable teacher development, reform of examination system, defining the entry and exit level competencies need to be ensured.

\section{References}

Afroze, R. K., \& Rahman, A. M. M. H. (2008). English teachers' classroom practices in rural secondary schools: An exploration of the effect of BRAC training. Bangladesh Education Journal, 7, 7-16.

Bachman, L. F., \& Palmar, A. S. (1984). Some comments on the terminology in the language testing. In C. Rivera, (Ed.), Communicative competence approaches to language proficiency assessment: Research and application (pp. 34-43). Avon: Multilingual Matters Ltd.

Clark, V. P., Escholz, P. A., \& Rosa, A. F. (Eds.). (1994). Language: Introductory readings. New York: St. Martin's Press.

ELTIP. (1998). Baseline survev of secondary English language teaching \& student proficiency. English Language Teaching Improvement Project, Dhaka, Bangladesh: Bangladesh Government Press.

English in Action. (2009). An assessment of spoken English competence among schools students, teachers and adults in Bangladesh. Retrieved from: http://www.eiabd.com/eia/baseline/Baseline\%20Study-1.pdf

English in Action. (2009). An Observation Study of English lessons in Primary and Secondary Schools in Bangladesh. Baseline Study Report. Retrieved http://www.eiabd.com/eia/baseline/Baseline\%20Study-3.pdf

Haider, M. Z., \& Roy, G. (2008). Present state of teaching and learning English in the secondary grades in Bangladesh. Conference on English language teaching in Bangladesh: Policy, practice and strategy, BUIED, Dhaka.

Hamid, M. O., \& Baldauf, R. B. (2008). Will CLT bail out the bogged down ELT in Bangladesh? English Today, 24, 16-24. http://dx.doi.org/10.1017/S0266078408000254

Hamid, M. O. (2005). Going communicative. Spectrum: Journal of the Department of English, University of Dhaka, 3, 38-49.

Hedge, T. (2000). Teaching and learning in the language classroom. Oxford: Oxford University Press.

Howatt, A. (1984). A History of English language teaching. Oxford: Oxford University Press.

Hymes, D. H. (1972). On communicative competence. In J. B. Pride \& J. Holmes (Eds.), Sociolinguistics: Selected Readings (pp. 269-293). Harmondsworth: Penguin.

Islam, M. M. (2011). Teachers' understanding and practice of CLT in Bangladesh. Language in India, 11(11). Retrieved from: http://www.languageinindia.com/nov2011/bangladeshteachersunderstandingcltfinal.pdf

Jones, C., \& Fortescue, S. (1987). Using computers in the language classroom. Harlow: Longman.

Khan, R. (2002). Impact assessment of an in-service teacher training programme in Bangladesh: A research report. Journal of NELTA, 7(1 \& 2), 34-46

Kiato, S. K., \& Kiato, K. (1996). Testing communicative competence. The TESOL Internet Journal, 2(5).

Littlewood, W. (1981). Communicative language teaching. Cambridge: Cambridge University Press.

Maley A. (1989). Down from the pedestal: Literature as resource. In R. Carter, R. J. Walker, \& C. G. Brumfit (Eds.), Literature and the Learner: Methodological Approaches. Cambridge: Modern English Publishers.

McNamara, T. (2000). Language testing. Oxford: OUP.

NCTB. (1996). Curriculum and syllabus. Dhaka: Higher Secondary Education Project and Secondary Education Project. 
Nunan, D. (1987). Communicative language teaching: Making it work. ELT Journal, 41(2). http://dx.doi.org/10.1093/elt/41.2.136

Rahman, A. M. M. H. (1999). English language teaching in Bangladesh: Didactics on the pragmatics of a language teaching policy. In T. Hunter (Ed.), Collected papers of the international conference on National and Regional Issues in English Language Teaching: International Perspectives (pp. 5-32).

Rahman, A. M. M. H. (2011). Proceedings from LECW, 11: $5^{\text {th }}$ BELTA International Conference, Dhaka.

Richards, J. C., \& Rogers, T. S. (1986). Approaches and methods in language teaching: A description and analysis. Cambridge, UK: Cambridge University Press.

Rogers, T. S. (2001). Language teaching methodology. CAL online resources: Digest. September, 2001 Issue. Retrieved from: http://www.cal.org/resource/digest/rodgers.html

Trudgill, P., \& Hannah, J. (2002). International English: A guide to varieties of Standard English (4th ed.). London: Arnold.

Widdowson, H. G. (1978). Teaching language as communication. Oxford: Oxford University Press.

Wright, S. (2000). Community and communication: The role of language in nation state building and European integration. Clevedon: Multilingual Matters.

\section{Appendixes}

Appendix 1. Classroom Observation Checklist

[Please record your observation findings by giving a number from 1-5 to show the level of agreement to each of the statement below. $1=$ strongly disagree, 5 = strongly agree $]$

$\square$ Strongly agree $\square$ mostly agree $\square$ agree $\square$ disagree $\square$ strongly disagree

1. The teacher used English as the medium of instruction throughout the lesson.

2. The teacher used warm-up activities at the beginning of the lesson.

2. The teacher asked the students to read texts silently.

3. The teacher did pre-reading activities before asking students to read a text.

4. The teacher asked students to read a text aloud.

5. The teacher read the text aloud.

6. The teacher translated the English text in mother tongue.

7. The teachers introduced the grammatical items relevant to the text.

8. The teacher used lots of grammatical explanations and structures.

9. The teacher asked students to memorize the grammatical rules.

10. The teacher pre-taught vocabulary items.

11. The teacher used a variety of techniques (showing pictures, giving examples, inferencing etc.) to present new vocabulary.

12. The teacher encouraged students to interact with fellow students.

13. The teacher organized pair/group works.

14. The students were speaking most of the time.

15. The teacher was speaking most of the time.

Appendix 2. Questions for Teachers' Interview

1. Do you think your classroom situation is suitable for CLT? Please explain.

2. What, according to you, are the roles of students in a CLT classroom?

3. What is the nature of interactions you like to promote in your lessons? Please explain.

4. How do you correct your students' mistakes? 
5. What should be the role of mother tongue in an English language classes?

6. What challenges do you face in implementing CLT in your classroom?

7. How do you think the features of CLT can be adjusted into your own classroom?

8. Do you have any other suggestion regarding successful implementation of CLT? 